\title{
INVESTIGATION OF VADOSE ZONE FLOW MECHANISMS IN UNSATURATED CHALK USING CROSS-BOREHOLE ERT.
}

\author{
Slater $^{1}$, L., Binley ${ }^{1}$, A.M., Zaidman ${ }^{2}$, M.D. and L. J. West ${ }^{2}$ \\ 1: CRES, Institute of Environmental and Biological Sciences, Lancaster, LAl 4YQ. \\ 2: Department of Earth Sciences, University of Leeds, Leeds, LS2 9JT.
}

\section{INTRODUCTION}

Groundwater resources are vulnerable to surface-derived contaminants resulting from human activity. The vadose zone is a natural barrier between contaminant sources and groundwater stored in aquifers. The fate of contaminants currently in transit within the vadose zone (as determined by operative transport mechanisms) is of political, economic and social concern. Hence techniques are required to investigate solute transport mechanisms within the vadose zone.

A hydrogeological tracer test is the most frequently used method for the investigation of transport in the vadose zone. Following surface tracer application, the subsurface distribution of tracer in time and space must be sampled. From this information solute transport characteristics are inferred. These tracer tests suffer from the following limitations: (1) the sampling method can be destructive; (2) characterisation of the tracer distribution is obtained from point measurements so spatial continuity of the information is poor; (3) what is seen is determined by the sampling location. The third point can be a great problem in heterogeneous media, such as fractured rock, where important preferential transport pathways can be overlooked.

Electrical monitoring during injection of a saline tracer is an alternative approach to the investigation of vadose zone transport processes. This tracer sampling process is nondestructive and the information obtained is spatially continuous. The method hence may be of significant value for the investigation of transport in heterogeneous media where multiple transport processes, and the location of preferential flow pathways, need to be identified. In this paper the value of cross-borehole electrical imaging (ERT) to characterise vadose zone transport is demonstrated.

\section{FIELD SITE AND ERT INSTRUMENTATION}

The field site is located on an interfluve of the UK Chalk aquifer in east Yorkshire. The vadose zone is about $80 \mathrm{~m}$ thick at this site. Nitrate levels, as sampled from abstracted water, have risen over the last decade. Increasing nitrate levels are the legacy of intensive fertiliser application to the farmland that covers the UK Chalk aquifer. Concern regarding the future quality of potable water has stimulated much interest in the transport characteristics of the vadose zone of the UK Chalk aquifer. Interest is particularly focused on the degree to which rapid, fissure controlled, bypass flow operates.

Two ERT boreholes, spaced $10 \mathrm{~m}$ apart, were drilled to a depth of $15 \mathrm{~m}$. An electrode array, consisting of 20 electrodes spaced at $0.75 \mathrm{~m}$ intervals, was installed in each hole. To ensure electrical contact, boreholes were back-filled with a chalk grout. Tracer injection was 
performed using an irrigation array ( $6 \mathrm{~m} \mathrm{x} 3 \mathrm{~m}$ area) with taps spaced at $0.25 \mathrm{~m}$ intervals. The tracer was $\mathrm{NaCl}$ with a conductivity of $8 \mathrm{~S} \mathrm{~m}^{-1}$. A tracer volume of 1960 litres was input over 56 hours. ERT monitoring was performed at periods during and after tracer injection. ERT datasets consisted of 500 independent measurements. Tomograms of resistivity change relative to a background dataset were reconstructed. ERT image reconstruction and field procedures are detailed elsewhere (LaBrecque et al., 1996; Slater et al., 1996).

\section{RESULTS AND DISCUSSION}

Resistivity changes during and following tracer injection are shown in Fig. 1 (darker shading represents decreased resistivity, white areas indicate no reduction). During tracer injection there is (1) a marked decrease in resistivity in the top $3 \mathrm{~m}$ that can be distinguished after only 8 hours and is fully developed after 31 hours, (2) little change in resistivity between 3 and about $7 \mathrm{~m}$, and (3) a non-uniform decrease in resistivity in the lower half of the section, between about $7 \mathrm{~m}$ and $15 \mathrm{~m}$ depth, that can be seen after 31 hours and is fully developed after 53 hours. The resistivity pattern below $7 \mathrm{~m}$.was essentially unchanged over the first twenty nine days after injection ceased (see Fig. 1d - f). After 71 days the resistivity at depth had recovered towards the background distribution and this recovery was confirmed by the data set collected after 154 days. After 297 days a response at depth was again observed. Lateral migration of tracer was monitored by surface electrical imaging and indicated that most of the tracer remained within the infiltration area.

It is assumed that the resistivity decreases are predominantly caused by a combination of an increase in pore water salinity and degree of saturation as tracer penetrates the chalk. Darker colours in the images indicate areas where change is observed: following this interpretation, tracer transport is assumed to be occurring through these areas. There are a total of 220 parameters ('sensors' of tracer migration) in each image. These 'sensors' are spatially continuous throughout the image plane. Such a sampling density would not be possible using standard hydrogeological instrumentation.

The large decrease in resistivity of the soil zone and upper $2 \mathrm{~m}$ of chalk (top $3 \mathrm{~m}$ or so) during tracer injection reflects rapid wetting. This decrease is persistent, which indicates that tracer entered the intergranular matrix of the weathered chalk blocks which do not drain easily. Resistivity significantly reduced in several regions below $7 \mathrm{~m}$ depth (Fig. 1c-f) so tracer transport to the lower half of the section must have occurred. This indicates the initiation of a hydraulically conductive preferential transport mechanism during tracer loading. This evidence for tracer transport to depths greater than $7 \mathrm{~m}$ must be reconciled with the fact that the zone between $3 \mathrm{~m}$ and $7 \mathrm{~m}$ depth shows little resistivity change. The suggested hydraulic interpretation is that preferential flow occurred between $3 \mathrm{~m}$ and $7 \mathrm{~m}$ depth via either a single natural fracture or a few, discrete, steeply inclined fractures of insufficient width to be resolved from electrical imaging. The resolution of the tracer below $7 \mathrm{~m}$ depth suggests that significant lateral spreading out of the fractures occurred at about $7 \mathrm{~m}$. This lateral spreading may have been caused by interception of the tracer by marl layers (such layers are known to be present at the study site). If this interpretation is correct, vertical heterogeneity in solute transport mechanisms has been identified at this site. Fig. le-f shows that below $7 \mathrm{~m}$ recovery towards the background resistivity distribution had occurred after 71 days. Fig. $1 \mathrm{~g}$ indicates that reactivation of preferential transport occurred following a period of heavy rainfall. This is significant as it indicates that this rapid transport mechanism can occur during periods of heavy natural loading. A hydraulic interpretation of the ERT response is given in Fig. 2. 


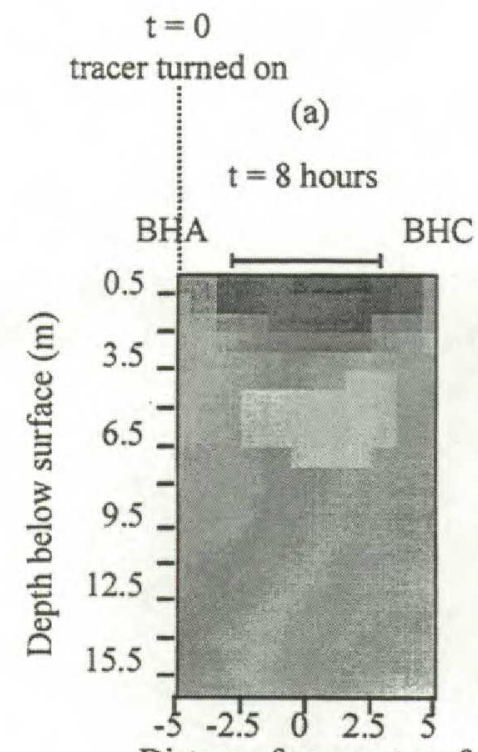

Distance from centre of boreholes (m)

(e)

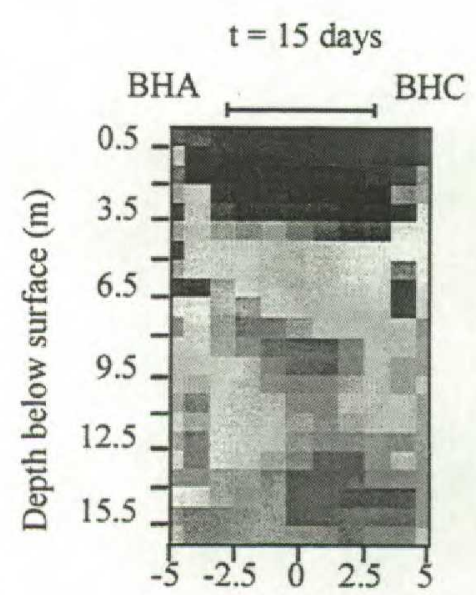

Distance from centre of boreholes (m)
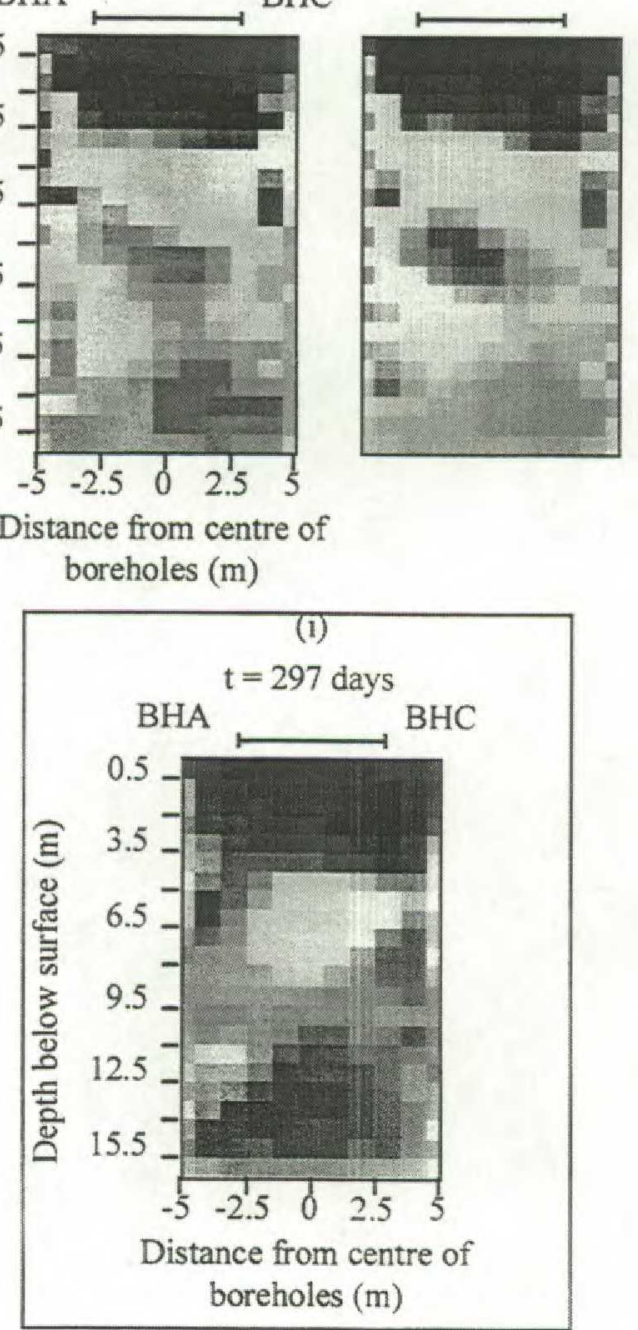

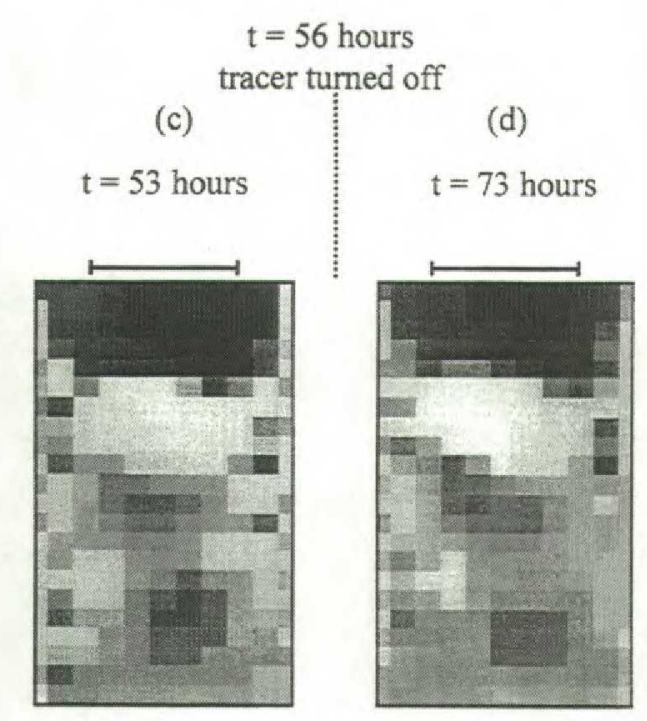

(g)

(h)

$\mathrm{t}=154$ days
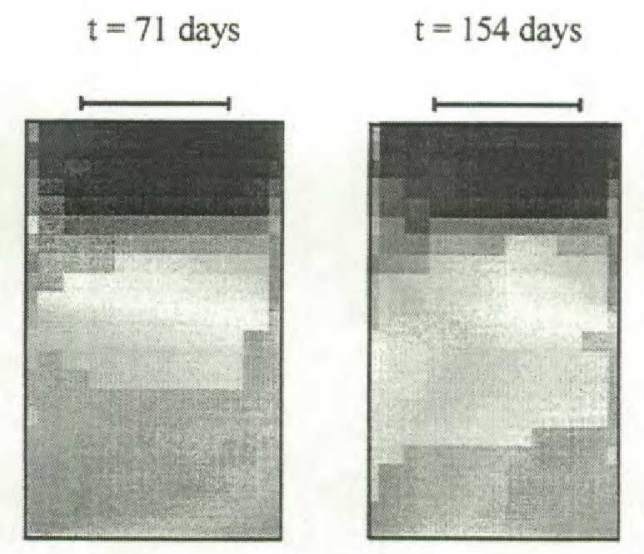
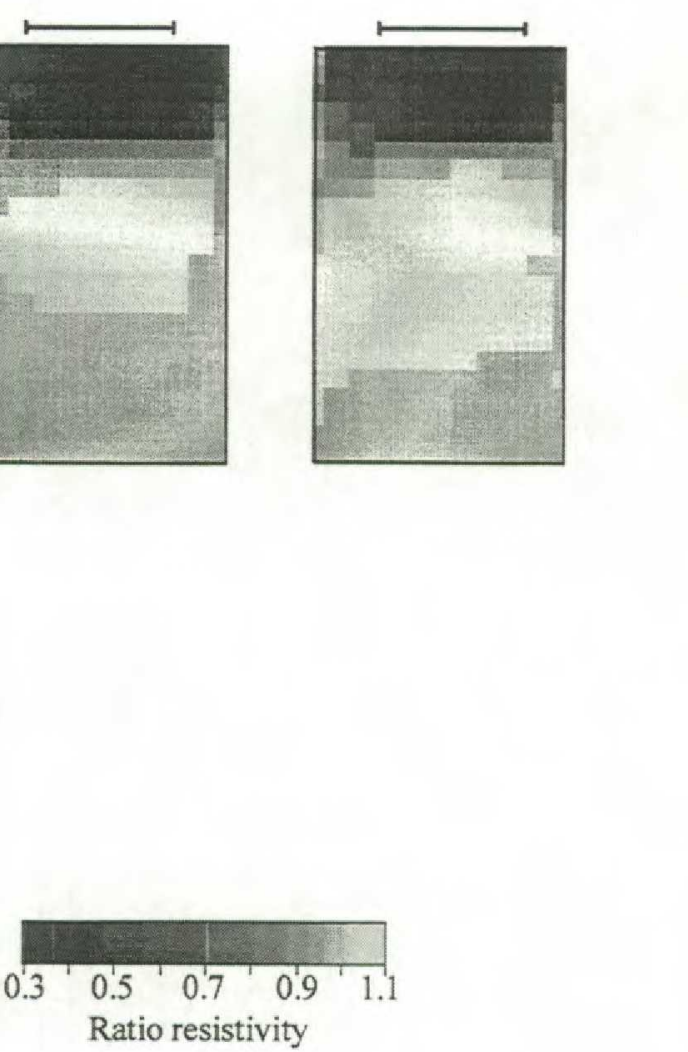


\section{CONCLUSIONS}

The value of electrical imaging of unsaturated zone transport mechanisms was illustrated by this study. High density, spatially continuous and non-invasive temporal sampling of operative transport processes was obtained. Assuming the hydrological interpretation of the electrical images to be correct, the images revealed the simultaneous operation of an intergranular and a fissure flow mechanism as well as vertical changes in transport mechanisms. This spatial information can help improve the description of solute transport at field sites and may be of value in the stochastic modelling of flow and transport. The integration of ERT monitoring with hydrogeological sampling of tracer tests is now required to further develop this geophysical approach to the characterisation of vadose zone transport.

\section{REFERENCES}

LaBrecque, D.J., Miletto, M., Daily, W., Ramirez, A. and Owen, E. 1996. The effects of noise on Occam's inversion of resistivity tomography data. Geophysics, 61. 538-548.

Slater, L.D., Brown, D. and Binley, A. 1996. Determination of hydraulically conductive pathways in fractured limestone using cross-borehole electrical resistivity tomography. European Journal of Environmental and Engineering Geophysics, 1. 35-52.

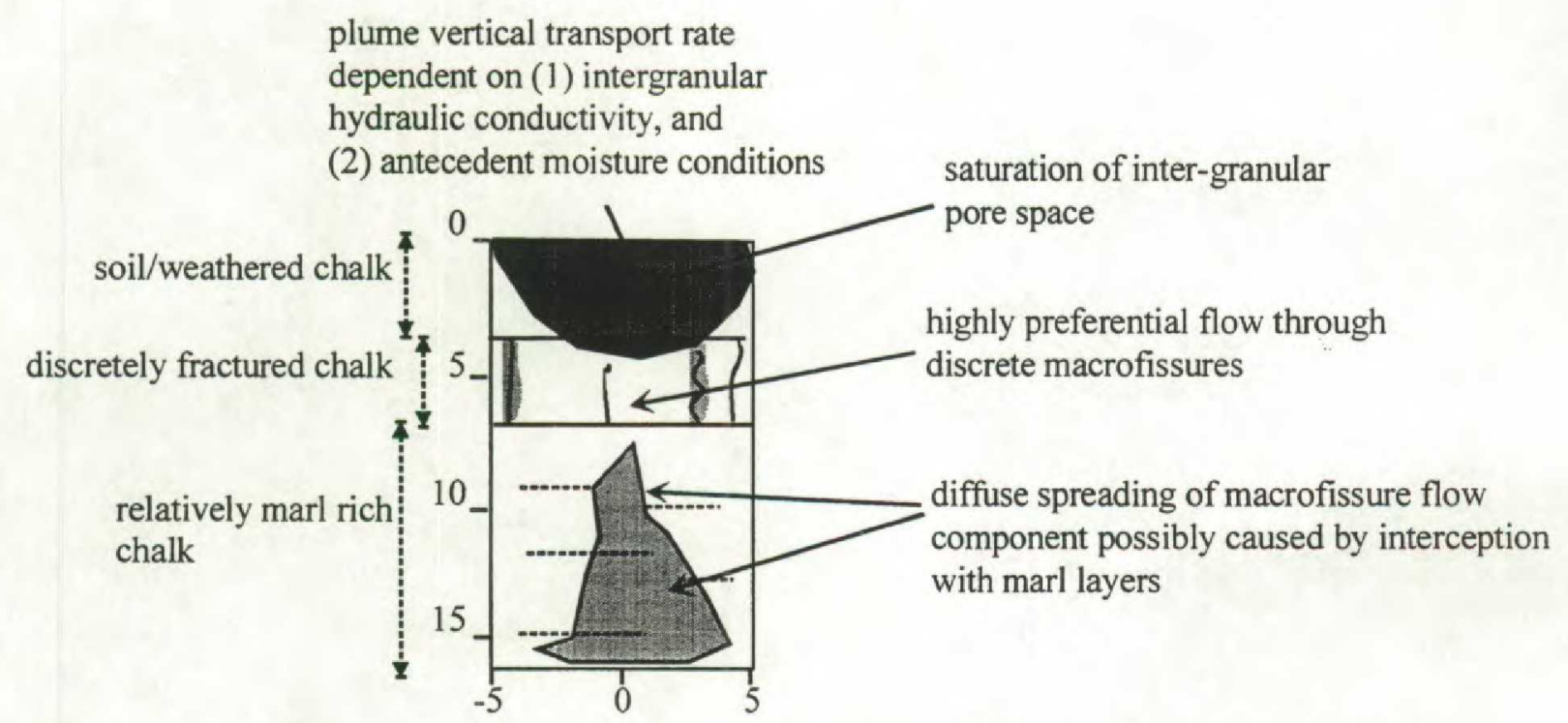

Figure 2: Schematic annotation showing postulated hydrological processes observed from ERT images. 